\title{
Application and Public Sector Focus of Public-Private Partnerships
}

\author{
(PPP) \\ Yaxi Wang \\ School of Economics and Management, Leshan Normal University, Leshan, Sichuan 614000, \\ China
}

Keywords: Public-private partnerships; application; risk; Public sector

\begin{abstract}
Public-Private Partnerships (PPP) models have been used for a longer period of time in countries around the world, it has become one of the core ideas and measures for many governments to achieve economic goals and enhance public service levels. Although PPP encountered some institutional confusion in China's practice, but China's public sector reform is one of the necessary institutional arrangements. In this paper, the underlying principles and advantages of PPP are introduced based on China's situation, this paper sets out themes which apply to all the various forms of PPP in China. Combined with the development of China's private economy and private capital, we explore the feasibility and advantages of the PPP model in the public sector, as well as the main mode of operation, stakeholder relationship, operational process and risk management.
\end{abstract}

\section{Introduction}

The importance of public utilities has been recognized by countries around the world. Public utilities projects are mostly long-term construction projects, huge investment in public welfare projects, which the government played an indispensable role. However, with the development of the society, the state finance is far from meeting the huge investment demand[1]. At the same time, the government has become a worldwide problem in the high investment, low efficiency and high consumption of resources in public utilities construction. PPP model is through the cooperation between the government and the private sector to develop public utilities to achieve the interests of all parties, while taking responsibility and financing risks. It is characterized by the greater use of the private sector and the reliance on government departments to meet the needs of the public[2-3].

Based on the study of relevant literatures at home and abroad, this paper analyzes the historical background and basic theory of PPP model, and focuses on the project financing of PPP model. Based on the analysis of the present situation of public utilities development and investment and financing in our country, this paper discusses the feasibility and advantage of introducing PPP model in China's public utilities construction, combining with the development of private economy and private capital in China[4]. It analyzes the main mode, stakeholder relationship and risk management of PPP mode in China's public utilities construction.

As a new mode of operation of the infrastructure project, the PPP model has its unique mode of operation and characteristics[5]. This chapter will combine the four aspects of China's national conditions from the mode of operation, project stakeholders and their responsibilities, project operation process and risk management Detailed analysis of PPP model in national project practice. 


\section{Analysis on the Operation of PPP Mode in China}

The main operation mode of PPP Mode in China. The existence of PPP model is based on the contract, the concession agreement and the ownership of ownership, on this basis can be used to achieve a variety of forms. According to China's actual situation, the PPP project implementation of the infrastructure projects can be used in a variety of different modes of operation[6]. Table 1 shows the different types of facilities for the application.

Table 1.The main operation of PPP projects in China's public utilities

\begin{tabular}{|c|c|}
\hline Type of public utilities & Applicable scope \\
\hline \multirow{4}{*}{ New utilities } & Build-Transfer-Operate, BTO \\
\hline & Build-Operate-Transfer, BOT, BOOT \\
\hline & Build-Own-Operate-Transfer, BOOT \\
\hline & Build-Own-Operate, BOO \\
\hline \multirow{2}{*}{ Already existing utilities } & Service Contract \\
\hline & Operations and maintenance contract or lease \\
\hline \multirow{3}{*}{$\begin{array}{c}\text { Expansion of existing } \\
\text { facilities }\end{array}$} & Lease-Build-Operate, LBO \\
\hline & Wraparound Addition \\
\hline & Build-Operate, BBO \\
\hline
\end{tabular}

The project of PPP model strongly related to and its main responsibilities. Project stakeholders are those individuals and organizations that are actively involved in the project or whose interests are affected by the project. Interests in projects operating in PPP mode typically include government, SPC, gold institutions, consulting firms, engineering contractors, raw material suppliers, and subscribers. Their relationship is shown in Figure 1.

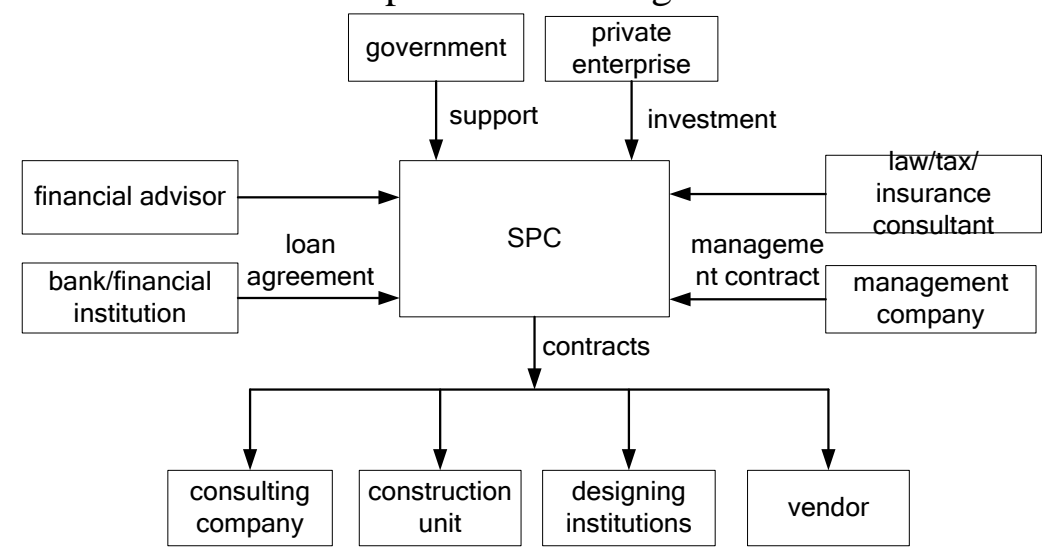

Figure 1. PPP model of project stakeholder relationship structure

Operation Process and Risk Management of PPP Project. A complete infrastructure project in PPP mode can be divided into four phases: pre-analysis, selection of SPC, development operations and transfer suspension, In the PPP model, the pre-analysis of the project includes two parts: project selection and feasibility study[7]. The choice of SPC is an important part of the operation of the project. SPC which from the launch to the successful registration usually go by through the tender, SPC primary, negotiation, signing and other links. The choice of SPC is an important part of the operation of the project.

Risks generally refer to the potential for the event. It has several aspects: risk is an uncertainty: risk is loss or damage; risk is the difference between expectations and consequences. Each participant's risk management approach is roughly the same as the process, as shown in Figure 2. 


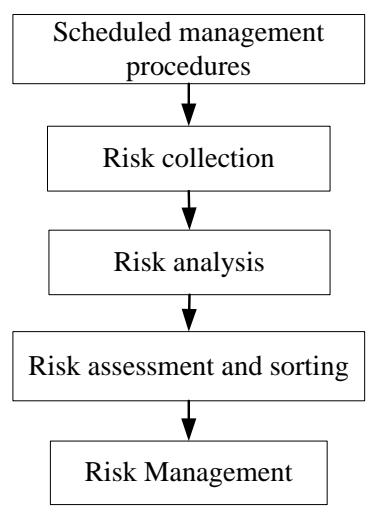

Figure 2.The risk management diagram of each participant in the PPP model

\section{PPP model in China's public sector applications and countermeasures}

Some Problems Should Be Considered in the Application of PPP Mode in China 's Public Utilities. The PPP model is suitable for projects with large investment amount, long construction period and slow recovery. It mainly focuses on the transportation business of railway, highway and other transportation departments, power and gas, and telecommunications networks[8-9]. Therefore, the PPP model in China has a wide range of development prospects, its introduction and use of China's public utilities to improve the "bottleneck" situation has an important role.

As a result, China's public utilities construction is the use of a single model of government financial allocations, while the legal private capital and private enterprises to participate in public infrastructure construction is also a lack of clear provisions, therefore, at this stage PPP in China's public utilities The application of the project needs to consider the following questions.

The first one is the role of government needs to change, the model that by the financial investment to support infrastructure construction has become increasingly unable to meet the growing needs of the socio-economic. The government should be the leading role in infrastructure construction in the past, to cooperate with the private sector to provide public services in the supervision.

The second is to develop a sound promotion program actively. PPP model has been widely used in developed countries and has been successful, PPP model has just started in our country, so the government should seriously study the PPP model and its application prospects in China. With the PPP model in the construction of public utilities, the domestic private enterprises and private consortia should seize this opportunity to participate in public utilities construction projects.

Shrink down the public and private in the construction of business philosophy and institutional differences. The government carry out public utilities construction is mainly from the perspective of public welfare, in order to meet the needs of end-users, leading to initial investment, high operating costs and project economic efficiency is difficult to achieve the desired goal, which may make the government bear heavy burden. The private enterprises which from the commercial point of view will more hope to gradually increase the size of the project according to the project income in the implementation of the PPP project. Reducing the differences between the public and private business philosophy and the system is an important factor in the success of the PPP project. In this regard, the government should actively learn from the experience of foreign PPP projects, with the help of the strength of professional organizations, efforts to narrow the differences between the two companies to explore the implementation of public utilities PPP project implementation.

Improve the financing channels in the public sector and reduce the financing costs. At present, China's public utilities project in the domestic financing of the main channels of 
commercial bank loans and listing financing, high cost which for the PPP project financing is extremely unfavorable. In order to ensure the smooth implementation of PPP projects, we must consider further raising the financing channels and reducing the financing costs.

The first is to relax restrictions on the use of national policy bank loans and foreign government loans. As a result of certain policy restrictions on the development of private capital, it is difficult for private enterprises to participate in the PPP project to use conditional preferential national policy bank loans and foreign government loans. Although the recent countries have identified, in the normative guarantee conditions, allow domestic enterprises to borrow foreign government loans, but there is no clear legal guidance, if these problems are not resolved, it is difficult to use preferential loans to promote the implementation of PPP projects.

The second is to allow insurance funds, social security funds, housing funds and other large funds to invest in public utilities PPP project. Insurance funds, social security funds, housing funds and other large funds, it is necessary to guard against financial risks. Public utilities PPP project investment cycle is long. The stable returns, is very suitable for the above-mentioned various fund investment, if there is policy support, then the operating pressure of such funds will be easily.

\section{Summary}

PPP model is to improve the quality of public utilities, to achieve the win-win cooperation parties through the government public sector and the private sector, its production and application for the development of China's public sector provides is worth of thinking, as an important way of interaction between the government and the private sector. PPP model can be widely used in a variety of different public utilities construction. In addition, as a new project financing and operation, PPP model in the construction of public utilities is a worthy of in-depth discussion of the subject. As a result of the wide range of public utilities, different modes of operation of the public utilities in the implementation of PPP mode are also unfavorable, and the resulting distribution of public and private interests and the sharing of responsibilities need further investigation.

\section{References}

[1] Iossa E, Martimort D. The simple microeconomics of public - private partnerships[J]. Journal of Public Economic Theory, 2015, 17(1): 4-48.

[2] Engel E, Fischer R, Galetovic A. The basic public finance of public-private partnerships[J]. Journal of the European Economic Association, 2013, 11(1): 83-111.

[3] Rufín C, Rivera-Santos M. Between commonweal and competition: Understanding the governance of public-private partnerships[J]. Journal of Management, 2012, 38(5): 1634-1654.

[4] Liu T, Wilkinson S. Large-scale public venue development and the application of Public-Private Partnerships (PPPs)[J]. International Journal of Project Management, 2014, 32(1): 88-100.

[5] Kraak V I, Harrigan P B, Lawrence M, et al. Balancing the benefits and risks of public-private partnerships to address the global double burden of malnutrition[J]. Public health nutrition, 2012, 15(03): 503-517.

[6] Rowe S, Alexander N, Kretser A, et al. Principles for building public-private partnerships to benefit food safety, nutrition, and health research[J]. Nutrition reviews, 2013, 71(10): 682-691.

[7] Weir S J, DeGennaro L J, Austin C P. Repurposing approved and abandoned drugs for the treatment and prevention of cancer through public-private partnership[J]. Cancer research, 2012, 72(5): 1055-1058. 
[8] Ismail S. Critical success factors of public private partnership (PPP) implementation in Malaysia[J]. Asia-Pacific Journal of Business Administration, 2013, 5(1): 6-19.

[9] Effah Ameyaw E, Chan A P C. Identifying public-private partnership (PPP) risks in managing water supply projects in Ghana[J]. Journal of Facilities Management, 2013, 11(2): 152-182. 